Musées, Patrimoine et Culture scientifiques et techniques

$153 \mid 2014$

mai-juin 2014

\title{
Le soutien du ministère de la Culture et de la Communication au récolement des collections des muséums
}

Myriam Boyer

\section{OpenEdition}

\section{Journals}

Electronic version

URL: http://journals.openedition.org/ocim/1366

DOI: 10.4000/ocim.1366

ISSN: $2108-646 \mathrm{X}$

Publisher

OCIM

Printed version

Date of publication: 25 June 2014

ISSN: 0994-1908

\section{Electronic reference}

Myriam Boyer, « Le soutien du ministère de la Culture et de la Communication au récolement des collections des muséums », La Lettre de l'OCIM [Online], 153 | 2014, Online since 26 June 2016, connection on 30 April 2019. URL : http://journals.openedition.org/ocim/1366 ; DOI : 10.4000/ ocim. 1366 


\title{
Le soutien du ministère de la Culture et de la Communication au récolement des collections des muséums
}

\author{
Myriam Boyer \\ Conseiller pour les musées, DRAC Nord-Pas-de-Calais
}

Les muséums qui sont musées de France peuvent bénéficier au même titre que les 1220 musées de France de la politique de soutien pour le récolement mise en place par le ministère de la Culture et de la Communication.

À l'échelle nationale, le suivi de l'avancement du récolement décennal de chaque muséum, comme de l'ensemble des musées de France, est assuré à la Direction générale des Patrimoines par la sous-direction des collections et plus précisément par le Bureau de l'inventaire des collections et de la circulation des biens culturels. Ce bureau centralise les données concernant le récolement, collectées à l'échelle régionale par les conseillers pour les musées présents au sein des 26 Directions régionales des affaires culturelles (DRAC) et Directions des affaires culturelles (DAC) des départements d'Outre-Mer.

À l'échelle régionale, les DRAC-DAC veillent à l'avancement du récolement des musées de France dont les collections n'appartiennent pas à l'État conformément à la circulaire du 3 novembre 2010. Elles sont destinataires du plan de récolement, document programmatique qui permet d'appréhender l'opération de récolement dans la durée en fonction des collections et des moyens disponibles, et de la copie des procès-verbaux de récolement qui présentent les résultats de chaque campagne.

Les DRAC-DAC collectent les données permettant d'établir le taux d'avancement de récolement de chaque musée de France qui est, depuis 2011, l'un des indicateurs de performances des musées. Elles veillent au respect de la législation ce qui peut se traduire, si nécessaire, par le rappel à la loi.

Elles ont aussi et surtout un rôle important d'impulsion, de coordination et de sensibilisation des propriétaires des collections et des personnels à l'importance du récolement. Le conseiller pour les musées accompagne ainsi les muséums tout comme les autres musées de France, prodigue ses conseils pour la rédaction des plans de récolement et des procès-verbaux et apporte son expertise pour la mise en œuvre concrète du récolement. La DRAC Île-de-France a été associée à la réflexion menée par la Conférence Permanente des Muséums de France sur le récolement.
Plus généralement, les DRAC-DAC peuvent également subventionner, au titre du fonctionnement, des actions ponctuelles ayant un lien direct avec le récolement qui demeure une obligation légale de la tutelle. Pour les muséums, les DRAC-DAC peuvent, en fonction des situations locales, participer au financement d'un poste spécifique sur un temps donné, de missions, de vacations et de prestations externalisées, mais aussi de chantiers des collections et de publications valorisant les données issues du récolement.

L'aide financière apportée au récolement des collections des muséums est très contrastée selon les régions ce qui peut s'expliquer notamment par l'inégale répartition de ces derniers sur le territoire, par leur niveau d'avancement dans le récolement, par la taille des équipes et par le soutien apporté par ailleurs par le ministère de l'Éducation nationale, de l'Enseignement supérieur et de la Recherche, les DRAC étant attentives à intervenir en complémentarité avec ce dernier. Les muséums situés en Bourgogne, Pays de la Loire, Limousin et Aquitaine sont les plus aidés financièrement. Comparativement aux autres musées de France, les interventions financières à l'attention des muséums sont pour la plupart récentes, modestes et ne concernent que quelques régions. 